\title{
Response analysis of a nuclear containment structure with nonlinear soil-structure interaction under bi-directional ground motion
}

\author{
Santosh Kumar ${ }^{1,2} \cdot$ Prishati Raychowdhury $^{2} \cdot$ Prabhakar Gundlapalli $^{3}$
}

Received: 20 August 2014/ Accepted: 13 April 2015/Published online: 23 April 2015

(C) The Author(s) 2015. This article is published with open access at Springerlink.com

\begin{abstract}
Design of critical facilities such as nuclear power plant requires an accurate and precise evaluation of seismic demands, as any failure of these facilities poses immense threat to the community. Design complexity of these structures reinforces the necessity of a robust 3D modeling and analysis of the structure and the soil-foundation interface. Moreover, it is important to consider the multiple components of ground motion during time history analysis for a realistic simulation. Present study is focused on investigating the seismic response of a nuclear containment structure considering nonlinear Winkler-based approach to model the soil-foundation interface using a distributed array of inelastic springs, dashpots and gap elements. It is observed from this study that the natural period of the structure increases about $10 \%$, whereas the force demands decreases up to $24 \%$ by considering the soil-structure interaction. Further, it is observed that foundation deformations, such as rotation and sliding are affected by the embedment ratio, indicating an increase of up to $56 \%$ in these responses for a reduction of embedment from 0.5 to $0.05 \times$ the width of the footing.
\end{abstract}

Keywords Nonlinear analysis .

Soil-structure interaction - Nuclear containment .

Bi-directional ground motions

Prishati Raychowdhury

prishati@iitk.ac.in

1 Present Address: Indian Oil Corporation Ltd., New Delhi, India

2 Department of Civil Engineering, Indian Institute of Technology Kanpur, Kanpur, India

3 Nuclear Power Corporation of India Limited (NPCIL), Mumbai, India

\section{Introduction}

With increasing energy demand, use of nuclear energy has increased worldwide, which in turn led to construction of more number of nuclear power plants (NPP). Presently, there are about 437 operating nuclear reactors in 31 countries with a net installed capacity of $372 \mathrm{GW}$. In addition, 68 more plants with an installed capacity of $65 \mathrm{GW}$ in 15 countries are currently under construction. In India, 20 nuclear reactors are in operation with an installed capacity of $4780 \mathrm{MW}$ and 7 more reactors of $5300 \mathrm{MW}$ capacity are under construction (NPCIL 2012).

Increasing number of NPP have increased the concern for safety, as any structural damage to these nuclear reactors pose severe threat of radiation, major health concern as well as biological and environmental hazards. Nuclear disasters like Chernobyl, Russia in 1986 and more recently, Fukushima Daiichi, Japan in 2011 confirm the gravity of the situation. Earthquake is one of the important factors that can cause catastrophic structural damage to nuclear reactors. About one-fifth of the operating nuclear plants are located in seismically activity zones. In India, most of the existing and proposed nuclear reactors are situated in seismic zone II and III (Fig. 1). Hence, robust modeling techniques and stringent design methodologies should be ensured for the nuclear plant structures situated in seismic regions.

\section{Past research}

Housner (1960) pioneered the studies on soil-structure interaction (SSI) effects on nuclear reactors, theoretically indicating the possible effect of foundation rocking on structural response. In a subsequent remarkable study, 
Fig. 1 Location of NPPs and seismic zones in India

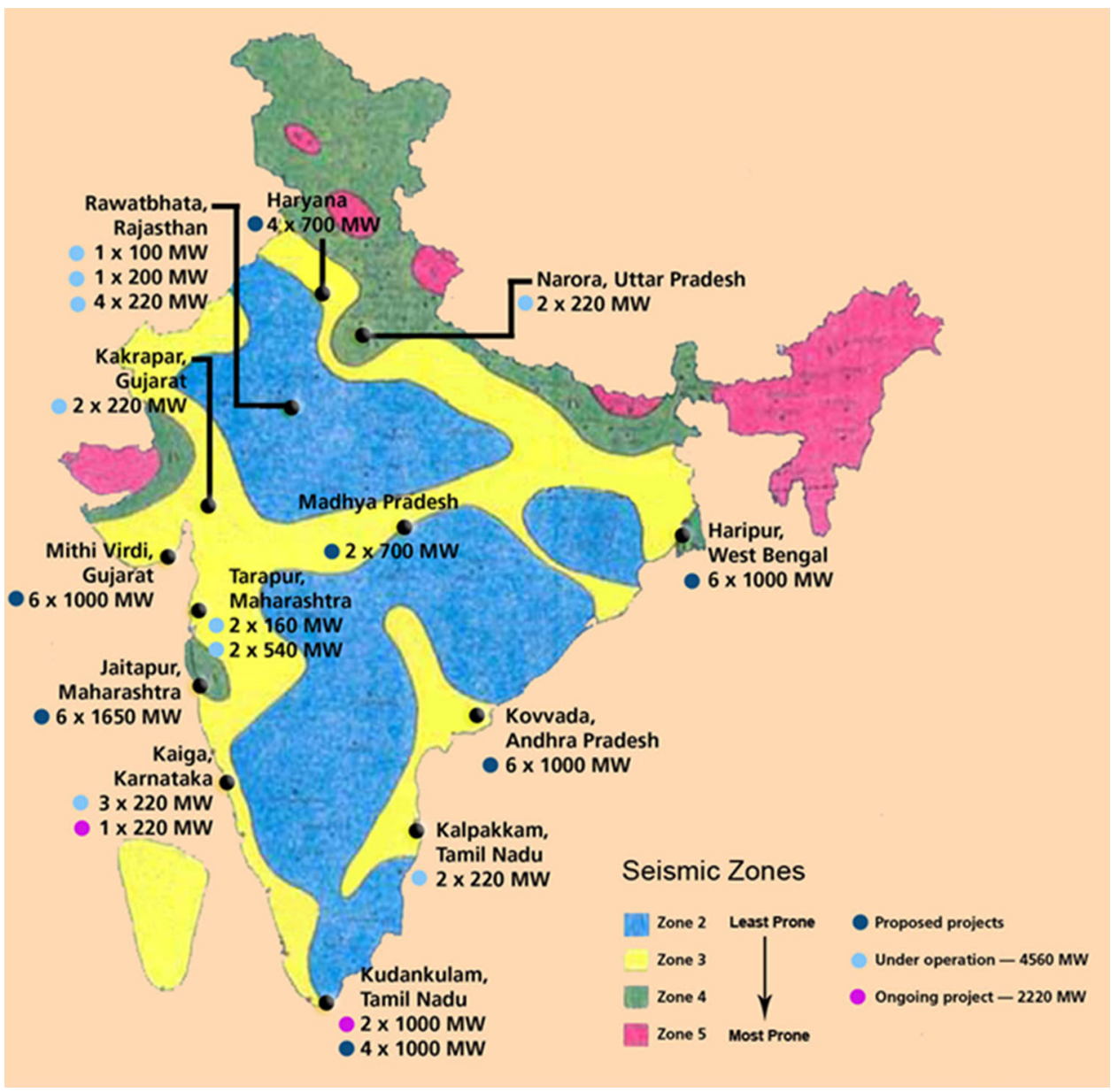

Newmark and Hall (1969) investigated the behavior of NPP facilities considering SSI. They observed the effect of site amplification and soil-foundation interaction on the seismic response of nuclear reactor structures. VenancioFilho et al. (1997) investigated the effect of dynamic soilstructure interaction on NPP containment structures by carrying out analytical studies using sub-structure and frequency domain methods. Kontani et al. (2004) studied the 3D effects of nonlinear SSI focusing on foundation uplift and soil nonlinearity by conducting extensive seismic vibration tests on the scaled model of an advanced boiling water reactor building.

Ghiocel (2009) studied the effect of seismic motion incoherency on the SSI response of a typical nuclear reactor building at a rock site, with and without mass eccentricities. They observed that the motion incoherency reduced the seismic response, especially for high frequency ranges. Nakamuraa et al. (2010) developed a three-dimensional nonlinear analysis model for containment structure considering SSI and basement uplift behavior to evaluate the building fragility for probabilistic safety assessment.
Saxena and Paul (2011) studied the effect of slip and separation due to SSI on seismic response of nuclear reactor building foundation system using 3D finite element analysis. Later, Saxena and Paul (2012) showed that horizontal slip of reactor base and vertical separation reduces with increase in embedment up to certain limit and then becomes insignificant. Bhaumik and Raychowdhury (2013) studied the seismic response of an internal shear wall of a reactor using 2D FE model considering nonlinear soil-structure interaction.

Most of the above-mentioned studies have either considered simplified structural model, or simplified elastic SSI model. Moreover, most of the studies have neglected the bi-directional effect of ground motion. Hence, to bridge the gap in the technology, present study is focused on investigating the seismic response of a nuclear containment building considering robust 3D finite element modeling including nonlinear soil-foundation interface, subjected to bi-directional earthquake ground motions. A nonlinear Winkler-based modeling approach is used to represent the soil-foundation interface. The main objective of this study is to investigate the effect of SSI and embedment ratio on 
several critical response parameters of the structure-foundation systems.

\section{Numerical modeling}

An overview of containment building details, structural properties, soil properties and numerical modeling approach for the structure-foundation-soil interface is presented herein. Details on ground motion selection and scaling criteria are also reported.

\section{Modeling of reactor containment structure}

In the present study, a containment structure has been adopted from Kudankulam NPP Project, located at $25 \mathrm{~km}$ northeast of Kanyakumari in the state of Tamil Nadu, India, along the coast of Gulf of Mannar. The project has two units of $1000 \mathrm{MWe}$ capacity reactors. The inner containment wall and dome are generally made of prestressed concrete, whereas the outer wall and outer dome are made of reinforced concrete. The internal structures are quite complex, comprising of reinforced concrete beams, columns, shear walls, floor slabs and prestressed concrete pressure walls. The main reactor building is rested on a raft foundation, which is $4.6 \mathrm{~m}$ thick at the center and $1.6 \mathrm{~m}$ thick at the ends. To reduce the complexity of modeling the raft foundation is assumed to be of constant thickness of $3.1 \mathrm{~m}$, an average of maximum and minimum thicknesses (as shown in Fig. 2). Also, the base slab is assumed to be resting above the ground surface with raft foundation at $5.35 \mathrm{~m}$ below it. The base slab of the containment building has thickness of $1.8 \mathrm{~m}$ and is $5.35 \mathrm{~m}$ above the foundation. The inner containment wall is $38.55 \mathrm{~m}$ high with a diameter of $44 \mathrm{~m}$, and a thickness of $1.2 \mathrm{~m}$. The hemispherical dome with a radius of $22 \mathrm{~m}$ lies on the top of containment wall (HCC 2010). More details can be found in Kumar (2013) and Bhattacharya and Raychowdhury (2014).

Numerical modeling of the above-mentioned containment structure with foundation has been developed in an open source finite element framework named as OpenSees (2009). The 3D model of the containment building used in the present study is shown in Fig. 3. Note from here onwards, $X$-direction is considered as lateral direction and $Y$ direction is considered as longitudinal. Four nodded 3D quadrilateral ShellMITC4 elements having 6 degrees of freedom are used to model the structure. This ShellMITC4 element uses a bilinear iso-parametric formulation in combination with a modified shear interpolation. The element is formulated using 3D continuum mechanics theory, and it is applicable to the analysis of thin and thick shells. Elastic material model is used to simulate the material for the containment structure, as the nuclear containment structures are designed to be within elastic limits under postulated design conditions.

A total number of 352 nodes and 320 elements are used for modeling the structural part (excluding the base slab, raft foundation and connectors). A convergence study has been performed to arrive at an optimum number of elements and nodes to be used in the modeling. Four models of the containment building have been developed for this purpose with 32, 80, 128 and 320 elements, as shown in Fig. 4. The convergence is examined for displacement in two horizontal directions $\left(D_{x}\right.$ and $\left.D_{y}\right)$ and moments $M_{x}, M_{y}$ and $M_{z}$, about $X, Y$ and $Z$ axis, respectively. The responses are recorded at a node located at the junction of the hemispherical dome and the containment wall. The node is marked in each model shown in Fig. 4. Results of the convergence study are presented in Fig. 5. It may be noted that the responses are presented in a normalized form. Normalization of the response for each response is done with respect to the response obtained from 4th model (i.e., the model with finest mesh configuration). Based on the convergence analysis, a structural model with 320 elements has been adopted for rest of the study. Mesh dimensions, material properties of the containment structure are summarized in Table 1.

\section{Modeling of base slab and raft foundation}

The shell element as discussed in the previous section is used to model the reactor base and mat foundation. To maintain the geometric continuity and consistent nodal connectivity with the containment model, the mesh size of the base slab and the raft are chosen to have 900 shell elements. This is required to create 961 modes for slab as well as for the raft foundation. Nodes of the base slab and the raft foundation had same $X$ - and $Y$-coordinate, but different $Z$-coordinate to represent varying thickness. The connection between the raft foundation and the base slab is modeled as rigid elastic columns using elastic BeamColumn elements. A summary of nodes and elements along with material properties adopted for modeling the base slab, raft foundation and the connector columns is provided in Table 1.

\section{Modeling of soil-foundation interface}

To model the soil-foundation interface, a beam-on-nonlinear-Winkler-foundation model, adopted from Raychowdhury and Hutchinson (2009) has been utilized. This model is capable of capturing soil yielding and degradation (soil material nonlinearity), as well as uplift, loss of contact and sliding of the foundation (geometric nonlinearity). The soil-foundation interface has been modeled as an array of 
Fig. 2 Schematic of nuclear containment structure used in the present study

Fig. 3 Numerical modeling of different components of the nuclear containment structure
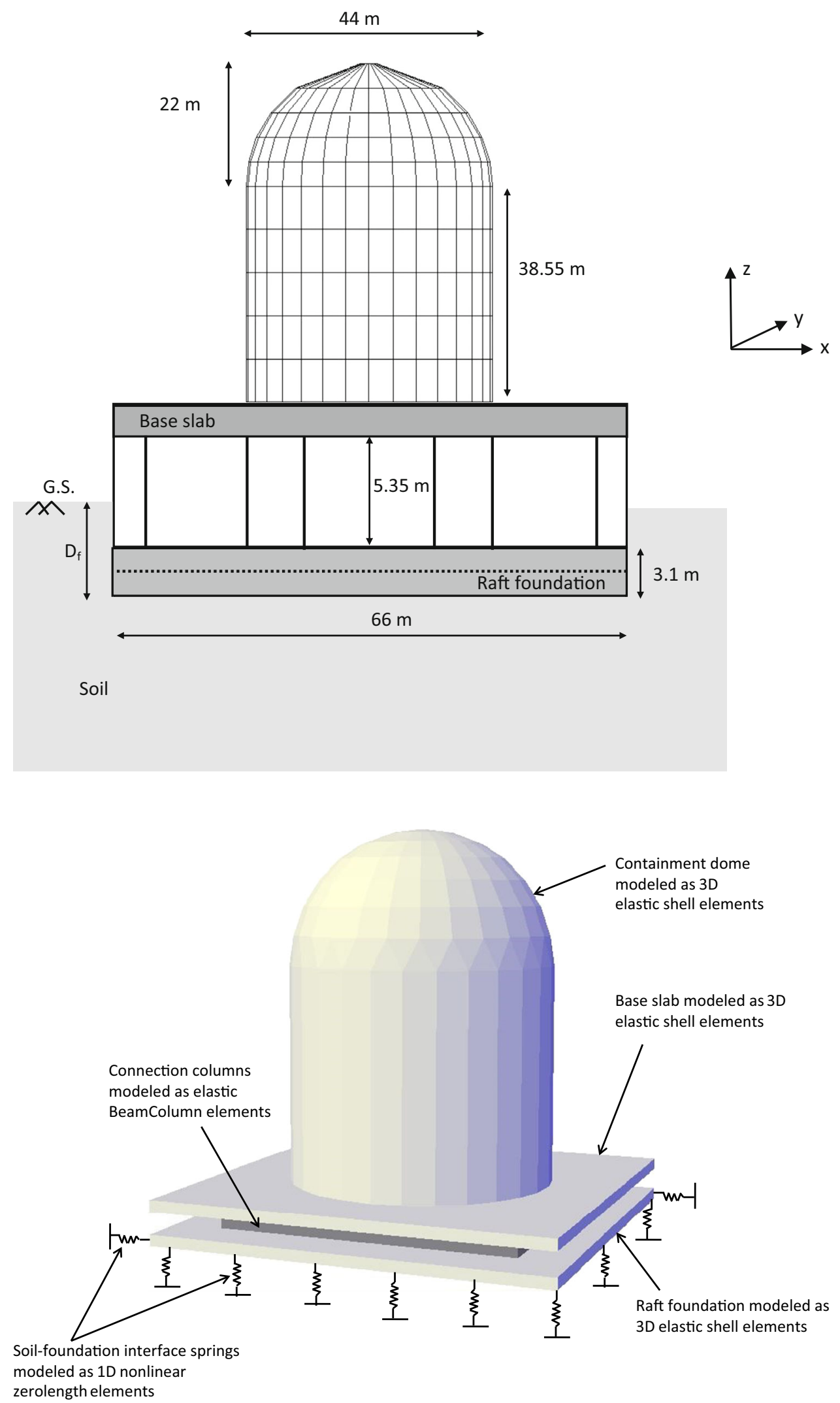


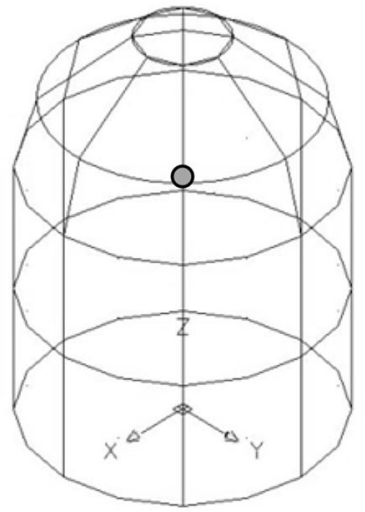

(a)

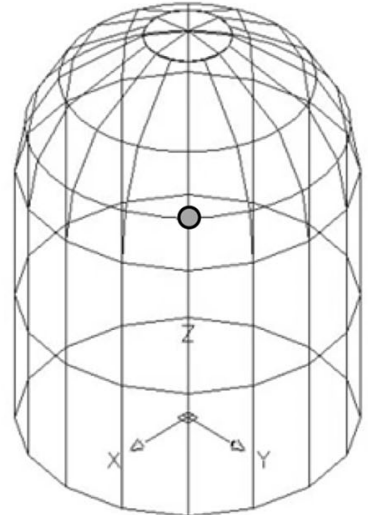

(b)

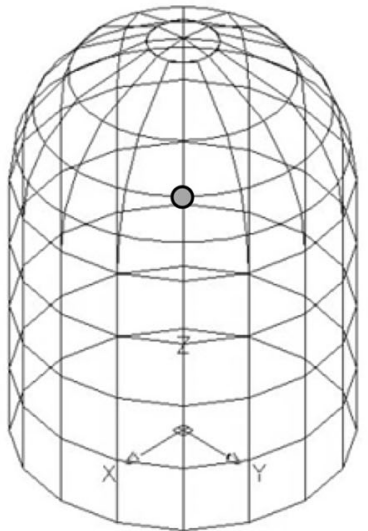

(c)

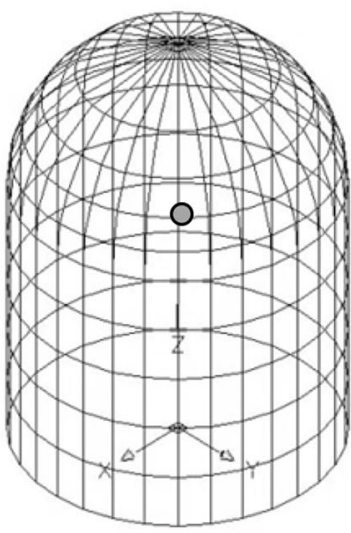

(d)

Fig. 4 Models used for convergence study. a 32 elements. b 80 elements. c 128 elements. d 320 elements
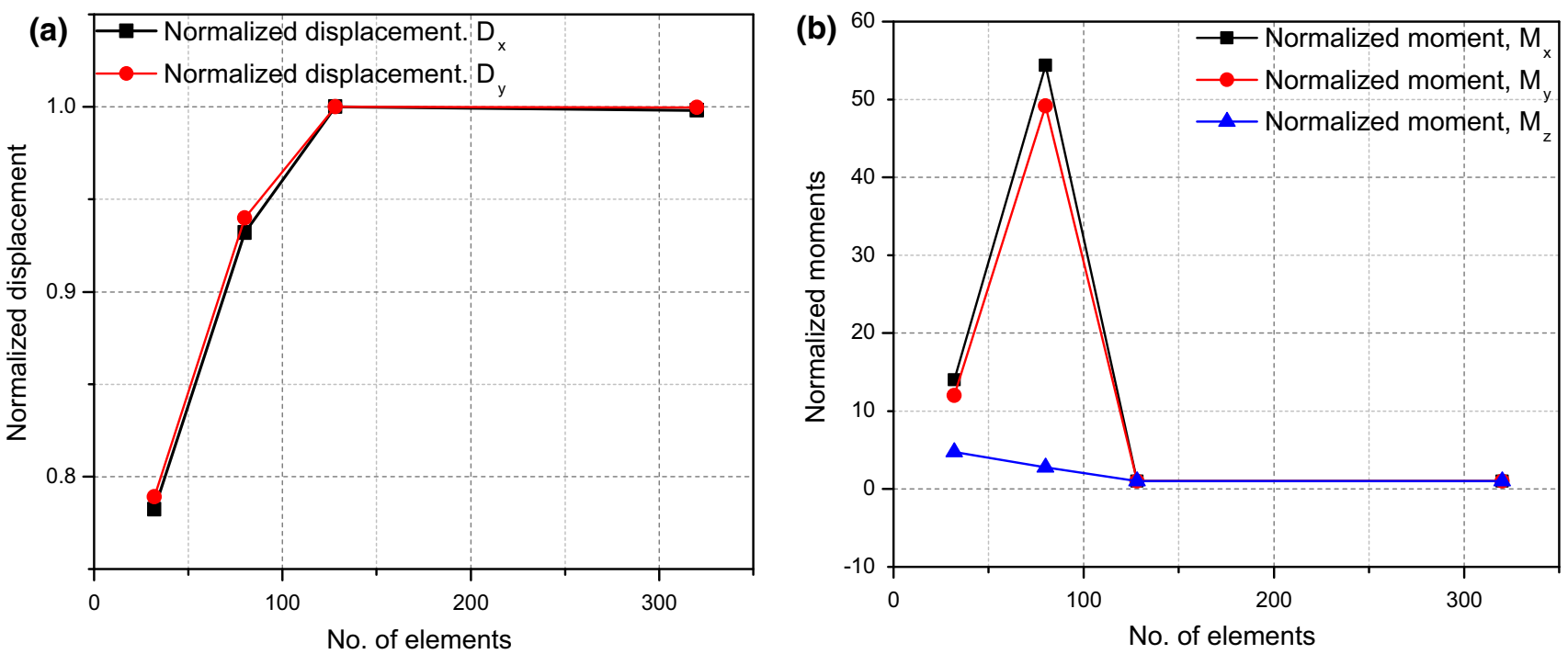

Fig. 5 a Normalized displacements versus number of elements and b normalized moments versus number of elements for convergence study

Table 1 Details of the containment modeling parameters

\begin{tabular}{llll}
\hline Parameters & Containment dome & Base slab & Foundation \\
\hline No. of nodes & 352 & 961 & 961 \\
No. of shell elements & 320 & 900 & 900 \\
Modulus of elasticity $(\mathrm{GPa})$ & 30 & 30 & 30 \\
Poisson's ratio & 0.2 & 0.2 & 0.2 \\
Density $\left(\mathrm{kg} / \mathrm{m}^{3}\right)$ & 2400 & 2400 & 2400 \\
Thickness $(\mathrm{m})$ & 1.2 & 1.8 & 3.1
\end{tabular}

closely spaced springs coupled with dashpots and gap elements. The vertical $q-z$ springs at the base of the raft is intended to capture the rocking, uplift and settlement. Horizontal $t-z$ springs are at the base to account for the frictional resistance at the base, whereas vertical $t-z$ springs are used at the sides of the footing to account for side friction. Further, $p-y$ springs are used in the $X$ - and $Y$ directions in the horizontal plane to capture the lateral resistances in both directions. A schematic with various types of springs along with their orientation is shown in Fig. 6a.

The constitutive relations associated with the $q-z, p-$ $y$ and $t-z$ springs are represented by material models 


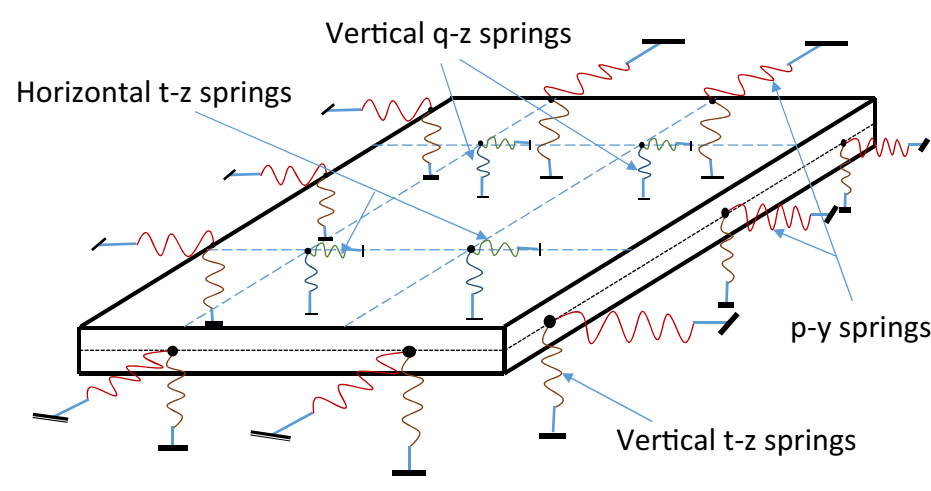

(a)

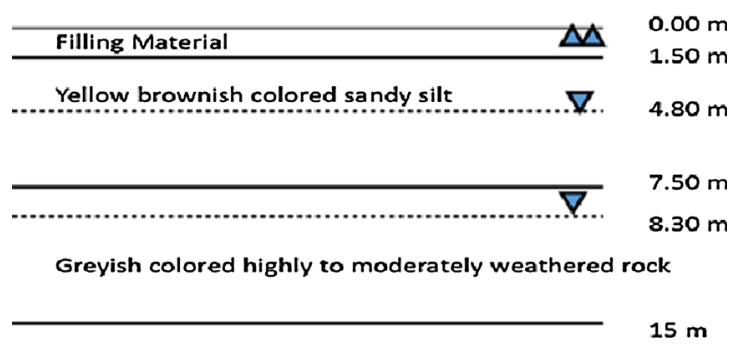

Greyish colored basalt rock
$35 \mathrm{~m}$

(b)

Fig. 6 a Raft foundation with various types of interface springs and their orientation and $\mathbf{b}$ soil profile with fluctuating water table

originally developed for piles by Boulanger et al. (1999) and later modified by Raychowdhury and Hutchinson (2009) through calibration against shallow foundation tests. In OpenSees framework, these material models are named as QzSimple1, PySimple 1 and $T z$ Simple1, respectively. In each of these material models, a visco-elastic component represents the far-field behavior and a plastic, drag and closure component captures the near-field displacement. A gap component accounts for soil-foundation separation is present in the QzSimplel and PySimplel materials. More details on these material models can be found in Raychowdhury and Hutchinson (2009, 2010, 2011).

In the present study, the raft foundation of the containment structure is designed for the soil condition at a given site in India. The soil profile is adopted from Bhaumik and Raychowdhury (2013) and shown in Fig. 6b. The raft foundation is assumed to be resting on second layer, i.e., the $6 \mathrm{~m}$ deep yellowish brownish colored sandy silt. Detailed soil properties of this layer are provided in Table 2. For vertical $q-z$ springs, the ultimate capacity is calculated based on Terzaghi (1943) with bearing capacity factors,

Table 2 General soil properties of the considered deposit

\begin{tabular}{ll}
\hline Soil properties & Value \\
\hline Natural moisture content $\left(w_{n}\right)$ & $22-43 \%$ \\
Liquid limit $(\mathrm{LL})$ & $47-72$ \\
Plastic limit $(\mathrm{PL})$ & $25-42$ \\
Cohesion $(c)$ & $23 \mathrm{kPa}$ \\
Friction angle $(\varphi)$ & $15^{\circ}$ \\
Unit weight $(\gamma)$ & $24.8 \mathrm{kN} / \mathrm{m}^{3}$ \\
Specific gravity $\left(G_{\mathrm{s}}\right)$ & $2.25-2.82$ \\
Corrected $\mathrm{N}_{60}$ & 10 \\
\hline
\end{tabular}

shape factors and depth factors after Meyerhof (1963), whereas the stiffness of vertical and lateral springs are calculated based on recommendations given by Gazetas (1991). The details of the calculated spring properties are tabulated in Table 3.

\section{Ground motion selection and scaling protocol}

A set of ten ground motions is considered to carry out dynamic analyses. The motions are chosen from Indian earthquakes and obtained from COSMOS virtual data center (COSMOS 2010). Each motion is amplitude scaled in such a way that, they represent uniform intensity levels in terms of peak ground acceleration (PGA). The recommendation of Atomic Energy Regulatory Board (AERB 2003) for expected seismic intensity (in terms of PGA) in each NPP site in India is provided in Table 4.

Note that two levels of earthquake intensities, viz., S1 and $\mathrm{S} 2$ are considered for the design of structures of Indian NPP structures, where, S1 represents the maximum intensity expected to be experienced at the site once during the operating life of the NPP within 100 years; whereas the S2 level is the level of ground motion that has a much lower probability being exceeded, with a return period of 10,000 years or more. In the design, the S1 level ground motion corresponds to operating basis earthquake, and S2 level corresponds to the safe shutdown earthquake. Based on these recommendations, two intensity levels are chosen for the analysis to cover a wide range of seismicity of Indian NPP sites: intensity 1 with a PGA of $0.15 \mathrm{~g}$, and intensity 2 with a PGA of $0.30 \mathrm{~g}$. Since bi-directional motions are used, the PGA component is calculated in the following way to calculate the ground motion scaling factor. For this purpose $\overline{\mathrm{PGA}}$ has been used, where: 
Table 3 Properties of the soil-foundation interface spring elements

\begin{tabular}{|c|c|c|c|c|c|c|}
\hline $\begin{array}{l}\text { Interface } \\
\text { spring type }\end{array}$ & $\begin{array}{l}\text { Material model name } \\
\text { in OpenSees (2009) }\end{array}$ & $\begin{array}{l}\text { Connection to } \\
\text { the foundation }\end{array}$ & Direction & Purpose of use & $\begin{array}{l}\text { No. of } \\
\text { springs } \\
\text { used }\end{array}$ & $\begin{array}{l}\text { Material properties } \\
\text { (per individual spring) }\end{array}$ \\
\hline$q-z$ springs & QzSimple1 & Base & Vertical & $\begin{array}{l}\text { Vertical settlement and } \\
\text { rocking response }\end{array}$ & 841 & $\begin{array}{l}q_{\mathrm{ult}}=10,113 \mathrm{kN} \\
z_{50}=6.2 \times 10^{-4} \mathrm{~m}\end{array}$ \\
\hline$p-y$ springs & PySimple1 & Sidewall & $\begin{array}{l}\text { Horizontal (both } \\
\text { lateral and } \\
\text { longitudinal) }\end{array}$ & $\begin{array}{l}\text { Lateral resistance of soil } \\
\text { and passive resistance }\end{array}$ & 31 & $\begin{array}{l}p_{\mathrm{ult}}=219.73 \mathrm{kN} \\
y_{50}=5.88 \times 10^{-6} \mathrm{~m}\end{array}$ \\
\hline$t-y$ springs & TzSimple 1 & Base & $\begin{array}{l}\text { Horizontal (both } \\
\text { lateral and } \\
\text { longitudinal) }\end{array}$ & $\begin{array}{l}\text { Frictional resistance at } \\
\text { the base of the footing }\end{array}$ & 841 & $\begin{array}{l}t_{\mathrm{ult}}=105.70 \mathrm{kN} \\
y_{50}=1.0 \times 10^{-5} \mathrm{~m}\end{array}$ \\
\hline$t-z$ springs & TzSimple 1 & Sidewall & Vertical & $\begin{array}{l}\text { Frictional resistance at } \\
\text { the sidewall-soil } \\
\text { interface }\end{array}$ & 31 & $\begin{aligned} t_{\mathrm{ult}} & =99.83 \mathrm{kN} \\
z_{50} & =9.63 \times 10^{-6} \mathrm{~m}\end{aligned}$ \\
\hline
\end{tabular}

Table 4 PGA value of Indian NPP sites (AERB 2009)

\begin{tabular}{lll}
\hline NPP sites in India & PGA (g) S1 level & PGA (g) S2 level \\
\hline Tarapur (Maharashtra) & 0.10 & 0.20 \\
Kota (Rajasthan) & 0.05 & 0.10 \\
Kalpakkam (Tamil Nadu) & 0.078 & 0.156 \\
Narora (UP) & 0.15 & 0.30 \\
Kakrapar (Gujarat) & 0.10 & 0.20 \\
Kaiga (Karnataka) & 0.10 & 0.20 \\
Kudankulam (Tamil Nadu) & 0.05 & 0.15 \\
\hline
\end{tabular}

$\overline{\mathrm{PGA}}=\sqrt{\mathrm{PGA}_{x}^{2}+\mathrm{PGA}_{y}^{2}}$.

Table 5 summarizes the details of chosen ground motions including the scaling factors used to scale the motions. While conducting the dynamic analysis, the ground motion input acceleration has been applied at the base of the raft foundation (at the fixed nodes of the spring elements) in both $X$ - and $Y$-directions.

\section{Analysis procedure}

To understand the seismic behavior of the containment structure with foundation system, nonlinear dynamic analysis has been carried out with the following details: a $5 \%$ Rayleigh damping for the first two modes of vibration of the model; Newmark's method with solution parameters $\beta=0.25$ and $\gamma=0.5$ to conduct the transient analysis; and modified Newton method with a convergence tolerance of $1.0 \times 10^{-8}$ to solve the nonlinear equations. To ensure the convergence, in case of modified Newton method fails, Newton algorithm with line search, Newton algorithm with initial tangent method and Broyden algorithm have also been opted.

\section{Results and discussions}

The results are divided into two subsections focusing on: (1) effects of nonlinear SSI and (2) embedment ratio.

Table 5 Details of ground motions selected for the analysis

\begin{tabular}{|c|c|c|c|c|c|c|c|c|c|c|}
\hline Sl. no. & $\begin{array}{l}\text { Earthquake } \\
\text { event }\end{array}$ & $\begin{array}{l}\text { Recording } \\
\text { station }\end{array}$ & $\begin{array}{l}\text { Magnitude } \\
\left(M_{\mathrm{w}} \text { or } M_{\mathrm{s}}\right)\end{array}$ & $\begin{array}{l}\text { Hypocentral } \\
\text { distance }(\mathrm{km})\end{array}$ & $\begin{array}{l}\text { Site } \\
\text { geology }\end{array}$ & $\begin{array}{l}\mathrm{PGA}_{x} \\
(\mathrm{~g})\end{array}$ & $\begin{array}{l}\mathrm{PGA}_{y} \\
(\mathrm{~g})\end{array}$ & $\begin{array}{l}\text { PGA } \\
(\mathrm{g})\end{array}$ & $\begin{array}{l}\text { Scaling } \\
\text { factor } \\
\text { S1 level }\end{array}$ & $\begin{array}{l}\text { Scaling } \\
\text { factor } \\
\text { S2 level }\end{array}$ \\
\hline 1 & Bhuj (2001) & Ahmedabad & 7.0 & 239.0 & Soil & 0.106 & 0.080 & 0.133 & 1.131 & 2.262 \\
\hline 2 & Chamba (1995) & Chamba & 4.9 & 34.0 & Soil & 0.146 & 0.125 & 0.192 & 0.780 & 1.560 \\
\hline 3 & Chamoli (1999) & Gopeshwar & 6.6 & 17.3 & Rock & 0.360 & 0.199 & 0.411 & 0.365 & 0.730 \\
\hline 4 & Chamoli (1999) & Joshimath & 6.6 & 26.0 & Rock & 0.071 & 0.064 & 0.095 & 1.575 & 3.151 \\
\hline 5 & Dharamsala (1986) & Dharamsala & 5.3 & 33.3 & Rock & 0.187 & 0.175 & 0.256 & 0.586 & 1.172 \\
\hline 6 & India Burma border (1997) & Ummulong & 6.0 & 78.4 & Rock & 0.155 & 0.101 & 0.185 & 0.810 & 1.621 \\
\hline 7 & India Burma border (1988) & Baigo & 7.2 & 247.1 & Soil & 0.221 & 0.144 & 0.264 & 0.569 & 1.137 \\
\hline 8 & India Burma border (1988) & Berlongfer & 7.2 & 220.1 & Soil & 0.301 & 0.344 & 0.457 & 0.329 & 0.657 \\
\hline 9 & India Burma border (1988) & Diphu & 7.2 & 210.1 & Soil & 0.282 & 0.337 & 0.440 & 0.341 & 0.682 \\
\hline 10 & Uttarkashi & Kosani & 7.0 & 34.0 & Rock & 0.310 & 0.242 & 0.393 & 0.382 & 0.763 \\
\hline
\end{tabular}




\section{Effect of nonlinear SSI}

To investigate the effect of SSI on the containment response, eigenvalue analysis followed by nonlinear time history analyses has been performed. Eigenvalue analysis has been carried out to obtain the natural periods and mode shapes of the structure, as well as to observe the effect of base flexibility due to SSI on the modal parameters of the structure. It can be observed from Fig. $7 \mathrm{a}$ that the fundamental period shifts from 0.67 to $0.74 \mathrm{~s}$ ( $\sim 10.4 \%$ increase $)$ upon incorporating
SSI. This period elongation is a result of flexibility induced in the system due to foundation movements. Figure $7 \mathrm{~b}$ shows the period elongation ratio for different modes, indicating highest elongation in the fundamental mode. These results are within the range suggested by Marzban et al. (2011), which states that the period ratio can vary from 1 to 2.25 depending on the soil characteristics.

Figure $8 \mathrm{a}, \mathrm{b}$ shows the results obtained from dynamic time history analysis in terms of lateral and longitudinal shear force at the base of the containment for fixed and

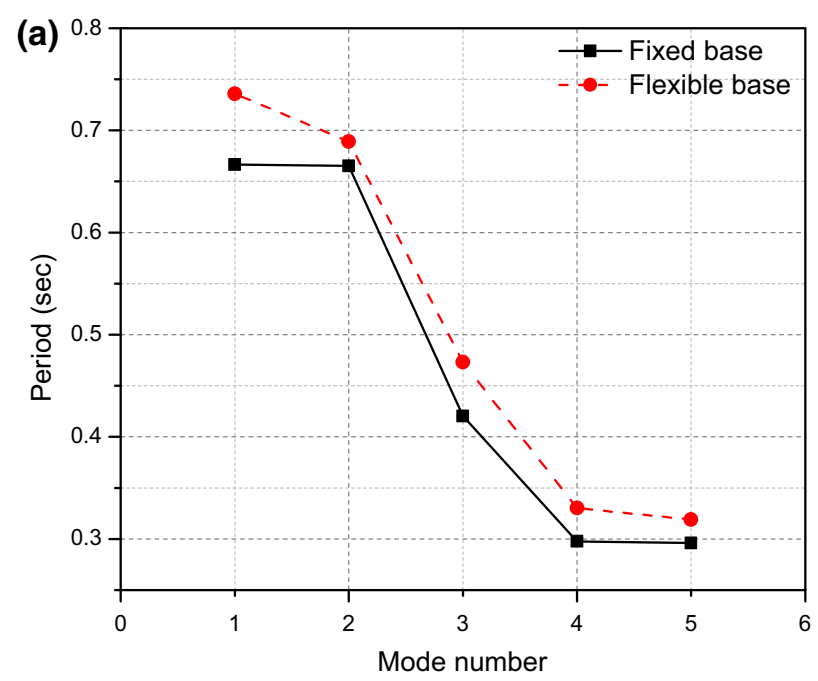

Fig. 7 a Effect of SSI on natural period; $\mathbf{b}$ period elongation ratio

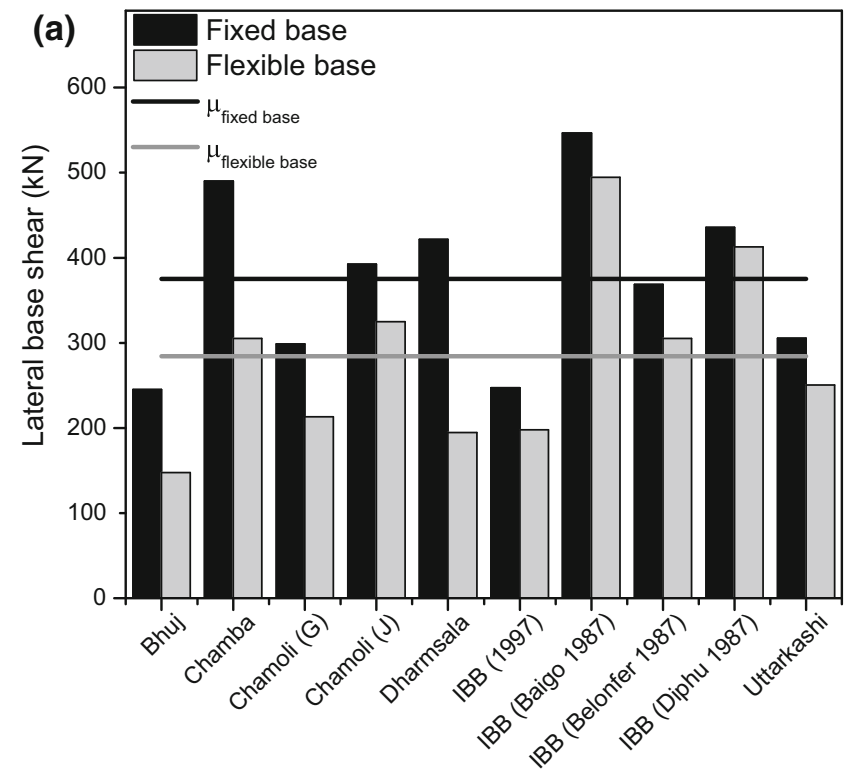

Earthquake (b)
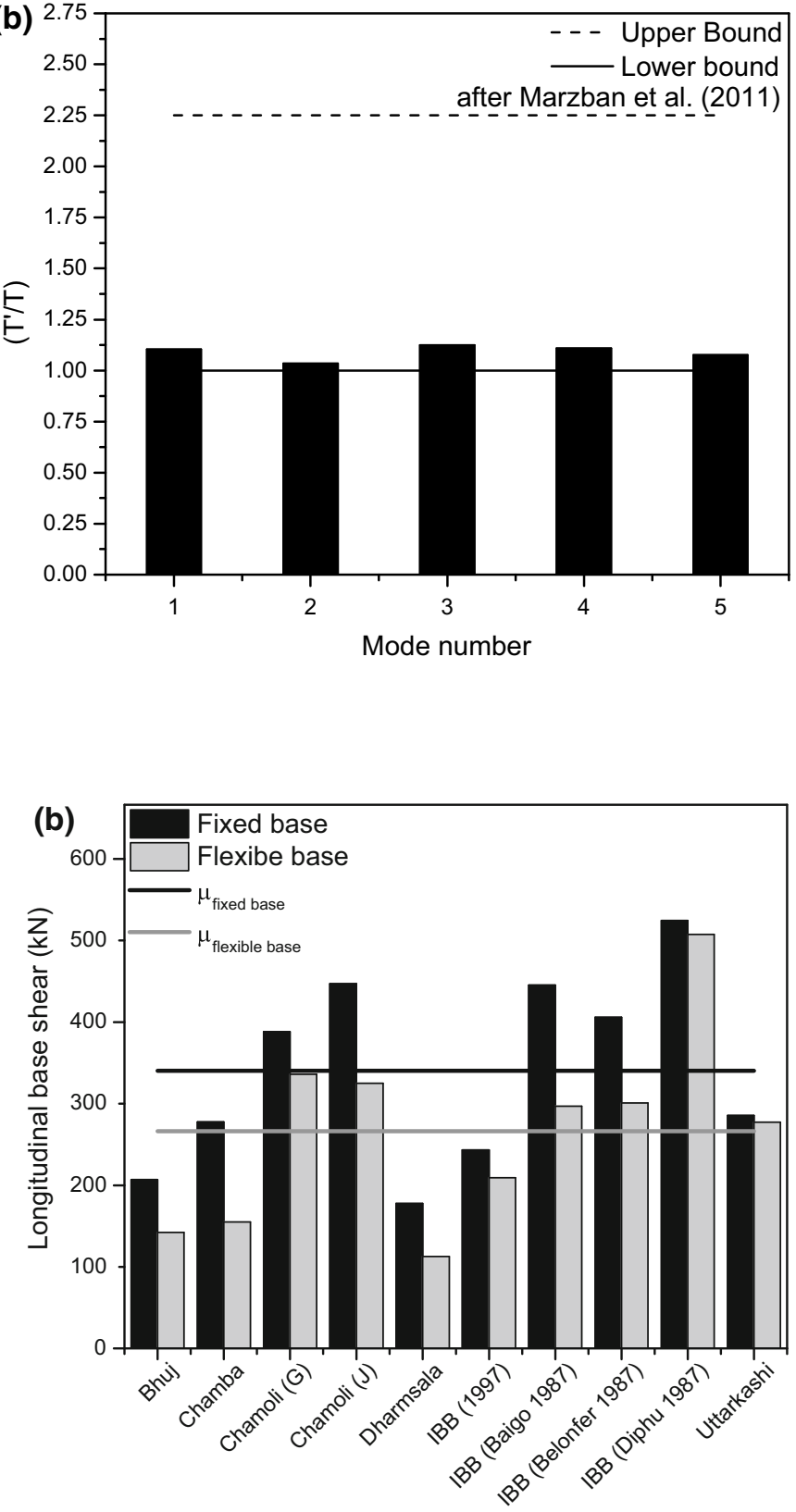

Earthquake

Fig. 8 Effect of nonlinear SSI on peak absolute base shear: a lateral direction and $\mathbf{b}$ longitudinal direction 


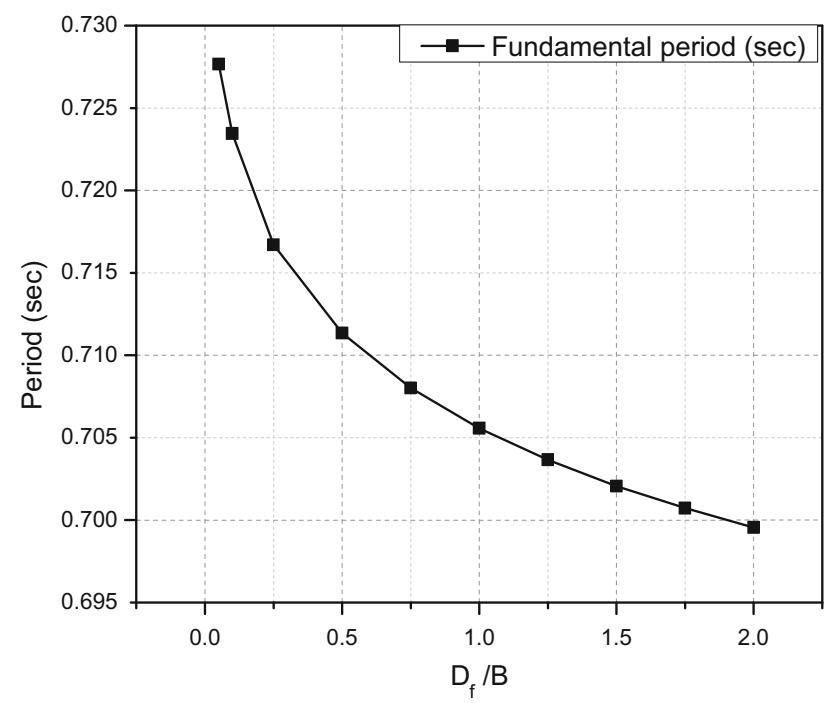

Fig. 9 Effect of embedment on natural period

flexible base systems for each ground motion. Moreover, the mean values for each case are also shown. It can be observed that there is about 24 and $21.7 \%$ decrease in the base shear in lateral and longitudinal directions, respectively, when SSI is considered. This may be due to the yielding of the springs at the soil-foundation interface and consequent energy dissipation. Similar effects have been seen for base moment too. More results and detailed discussion have been reported in Kumar (2013).

\section{Effect of embedment}

For heavy and rigid structure like reactor building, foundation embedment is an important factor, because a deeply embedded foundation is necessary to prevent these structures from slip and separation due to sliding and rocking. In this section, an effort has been made to address this issue by varying the depth embedment of the foundation and study its effect on different seismic demand parameters. First, the effect of embedment on the natural period of the structure-foundation-soil system is evaluated. The embedment depth to foundation width ratio $\left(D_{\mathrm{f}} / B\right)$ is varied from 0.01 to 2.0 for the eigenvalue analysis, and as expected, increasing depth of embedment results in reduced flexibility in the system leading to reduced natural period (Fig. 9).

The dynamic time history analyses are carried out for $D_{\mathrm{f}} / B=0.05,0.1,0.25$ and 0.5 , and the effect of embedment on peak rotation and sliding of the foundation in both lateral and longitudinal directions have been shown in Figs. 10 and 11. In addition to the peak responses for each ground motion, the mean and mean \pm standard deviation results are also shown to indicate an approximate range. It is observed that an increase of embedment from 0.01 to 0.5 leads to a change of up to $56 \%$ in the response value. The responses decrease consistently with increasing embedment, which is reasonable. Figure 10 shows variation in sliding in lateral and longitudinal direction indicating up to 55 and $56 \%$ increase in the mean response for decreasing embedment ratio from 0.5 to 0.05 . Figure 11 shows the variation of lateral and longitudinal foundation rotation, respectively, for varying $D_{\mathrm{f}} / B$ ratio. It is observed that when the embedment ratio is decreased from 0.1 to 0.05 there is 8.94 and $23.43 \%$ increase in lateral and longitudinal foundation rotation, respectively. Whereas when the embedment ratio is increased from 0.1 to 0.25 and then to 0.5 , there is percentage decrease of 33.44 and 51.06 in
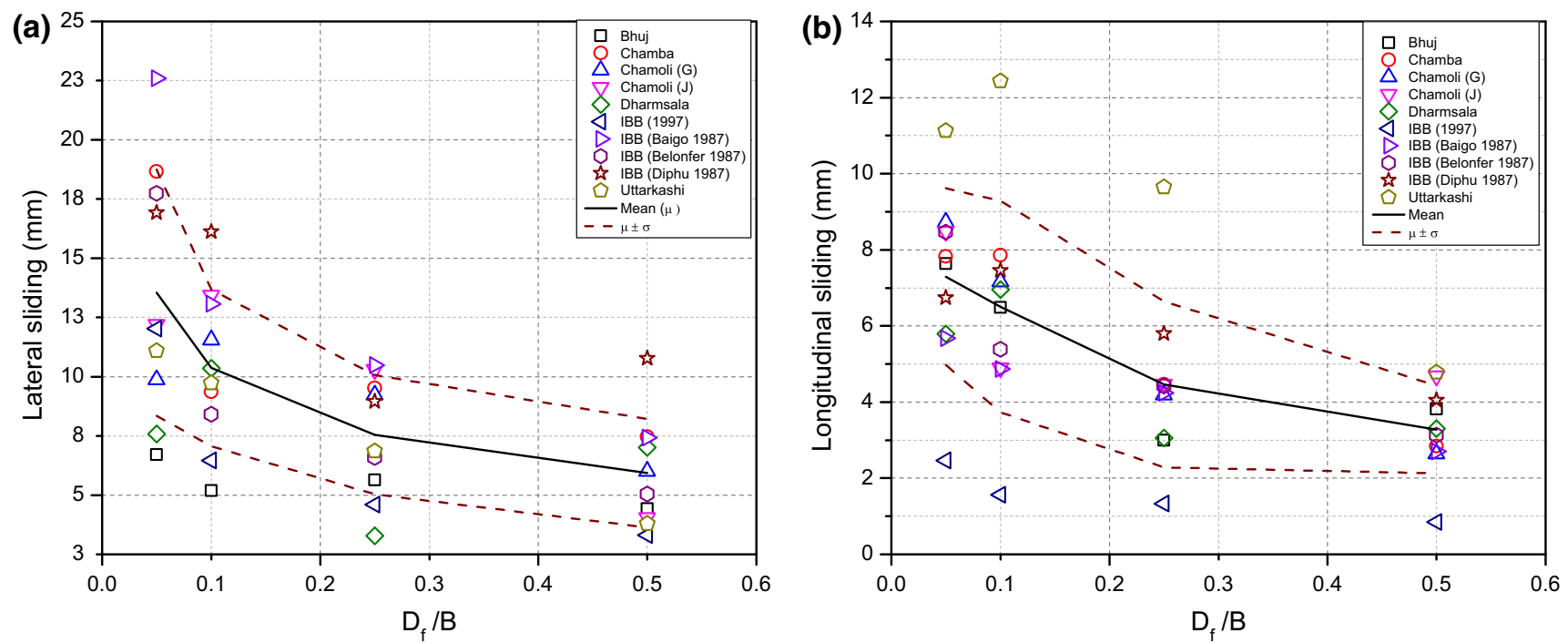

Fig. 10 Effect of embedment on foundation sliding: a lateral and b longitudinal directions 

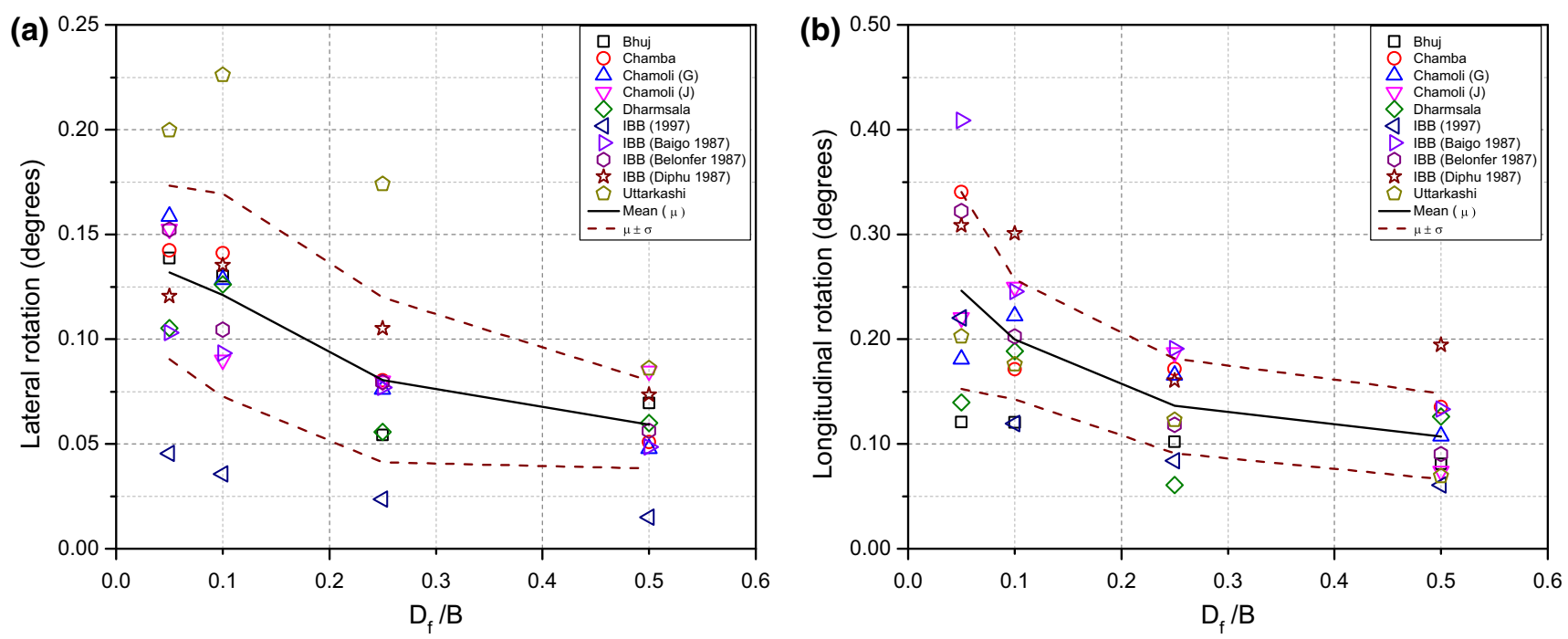

Fig. 11 Effect of embedment on foundation rotation: a lateral and $\mathbf{b}$ longitudinal directions

Table 6 Percentage change in response parameters with $D_{\mathrm{f}} / B$

\begin{tabular}{lllll}
\hline Parameter & \multicolumn{2}{l}{$D_{\mathrm{f}} / B$} & & \\
\cline { 2 - 5 } & 0.05 & 0.1 & 0.25 & 0.5 \\
\hline$u_{x}$ & 56.23 & 39.82 & 21.45 & 0 \\
$u_{y}$ & 55.05 & 46.95 & 26.49 & 0 \\
$\theta_{x}$ & 55.08 & 51.06 & 26.47 & 0 \\
$\theta_{y}$ & 56.52 & 46.33 & 21.38 & 0 \\
\hline
\end{tabular}

lateral rotation and 31.73 and 46.33 percentage reduction in longitudinal foundation rotation. This observation is in accordance with experimental observations by other researchers indicating the dependence of rotational demand and overturning resistance of buried components of structures. Foundation rotation is expected to be more when overturning resistance of the system is less. An increase in width of the footing and the vertical load also leads to increase the overturning resistance to some extent. The effect of embedment on each response parameter has been summarized in Table 6.

\section{Conclusions}

Design of critical structures, such as NPP requires very accurate and precise evaluation of seismic demands for earthquakes of wide intensity range. Design complexity of nuclear power buildings makes it necessary to perform three-dimensional modeling and analysis for accurately evaluating its behavior. Consideration of nonlinear SSI is also critical as it can alter the modal properties of the structures as well as the systems, equipment and components, depending on the ground motion intensity and local site conditions. Based on the analysis, the main conclusions of the present study are:

1. Fundamental period of the system increases from 0.67 to $0.74 \mathrm{~s}$ (10.4\% increase) upon inclusion of SSI, indicating an increased flexibility of the structure.

2. Base shear demand reduces on inclusion of SSI, as much as $24 \%$.

3. The embedment shows significant effect on the response of structure and foundation. Increasing embedment makes the system stiffer resulting in lower fundamental period.

4. Foundation deformations, such as, rotation and sliding are affected by the embedment ratio, indicating an increase of up to $56 \%$ in the rotation and sliding response for a reduction of embedment from 0.5 to $0.05 \mathrm{~B}$.

Open Access This article is distributed under the terms of the Creative Commons Attribution 4.0 International License (http:// creativecommons.org/licenses/by/4.0/), which permits unrestricted use, distribution, and reproduction in any medium, provided you give appropriate credit to the original author(s) and the source, provide a link to the Creative Commons license, and indicate if changes were made.

\section{References}

AERB (2003) Safety classification and seismic categorization for structures, systems and components of pressurized heavy water reactors. Report No. AERB/NPP-PHWR/SG/D-1, Atomic Energy Regulatory Board (AERB)

AERB (2009) Seismic qualification of structures, systems and components of pressurized heavy water reactors. Report No. AERB/NPP-PHWR/SG/D-23, Atomic Energy Regulatory Board (AERB) 
Bhattacharya S, Raychowdhury P (2014) Effect of fluctuation of ground water table on dynamic response of nuclear reactors. In: 15th symposium on earthquake engineering. Indian Institute of Technology, Roorkee

Bhaumik L, Raychowdhury P (2013) Seismic response of nuclear reactor buildings incorporating nonlinear soil-structure interaction. Nucl Eng Des (Elsevier) 265:1078-1090

Boulanger RW, Curras CJ, Kutter BL, Wilson DW, Abghari A (1999) Seismic soil-pile structure interaction experiments and analyses. J Geotech GeoEnvironmental Eng ASCE 125(9):750-759

COSMOS (2010) Consortium of organizations for strong motion observation systems. http://www.cosmos-eq.org/VDC/index. html

Gazetas G (1991) Formulas and charts for impedances of surface and embedded foundations. J Geotech Eng 117(9):1363-1381

Ghiocel DM (2009) Seismic motion incoherency effects on soilstructure interaction (SSI) response of nuclear power plant buildings. In: Proceedings, 10th international conference in structural safety and reliability, Osaka

HCC (2010) A project report on "making of Kudankulam Nuclear Power Plant" by Hindustan Construction Company

Housner GW (1960) Design of nuclear power reactors against earthquakes. In: Proceedings of 2 nd world conference on earthquake engineering, Japan

Kontani O, Suzuki A, Kitada Y, Iguchi M (2004) Experimental study on nonlinear soil-structure interaction of nuclear power plants using large scale blast excitations. In: Proceedings of third UJNR workshop on soil-structure interaction, Menlo Park

Kumar S (2013) 3D finite element modeling and seismic analysis of a nuclear containment structure. M.Tech. dissertation, Indian Institute of Technology Kanpur, India

Marzban S, Banazadeh M, Azarbakht A (2011) Seismic performance of reinforced concrete shear wall frames considering soilfoundation-structure interaction. In: Proceedings of 8th international conference on structural dynamics, Leuven
Meyerhof GG (1963) Some recent research on bearing capacity of foundations. Can Geotech J 1(1):16-26

Nakamuraa N, Akitab S, Suzukic T, Kobab M, Nakamurac S, Nakanod T (2010) Study of ultimate seismic response and fragility evaluation of nuclear power building using nonlinear three-dimensional finite element model. Nucl Eng Des 240(I): $166-180$

Newmark NM, Hall WJ (1969) Seismic design criteria for nuclear reactor facilities. In: Proceedings of 4 th world conference on earthquake engineering, Santiago

NPCIL (2012) Corporate profile, Nuclear Power Corporation of India Limited (NPCIL)

OpenSees (2009) OpenSees (open system for earthquake engineering simulation). Pacific Earthquake Engineering Research Center (PEER), University of California, Berkeley

Raychowdhury P, Hutchinson TC (2009) Performance evaluation of a nonlinear Winkler-based shallow foundation model using centrifuge test results. Earthq Eng Struct Dyn 38(5):679-698

Raychowdhury P, Hutchinson TC (2010) Sensitivity of shallow foundation response to model input parameters. ASCE J Geotech Geoenvironmental Eng 136(3):538-541

Raychowdhury P, Hutchinson TC (2011) Performance of seismically loaded shearwalls on nonlinear shallow foundations. Int J Numer Anal Methods Geomech 35(7):846-858

Saxena N, Paul DK (2011) Effects of slip and separation on seismic SSI response of nuclear reactor building. Nucl Eng Des 241:12-17

Saxena N, Paul DK (2012) Effects of embedment including slip and separation on seismic SSI response of a nuclear reactor building. Nucl Eng Des 247:23-33

Terzaghi K (1943) Theoretical soil mechanics. Wiley, New York

Venancio-Filho F, de Barros FCP, Almeida MCF, Ferreira WG (1997) Soil-structure interaction analysis of NPP containments: substructure and frequency domain methods. Nucl Eng Des 174:165-176 